\title{
Editorial:
}

\section{A Contemporary Outlook on Media and Gender}

\author{
Sandra Kaulfuss \& Nerina Boursinou
}

\section{Foreword}

Now in its $3^{\text {rd }}$ year, this issue of for(e)dialogue is offering a varied analysis of the developments in Media and Gender studies, as well as a contemporary discussion as to how the field has evolved and shaped the debates. From the early days of black and white cinema to modern day Hollywood, from traditional newspaper journalism to 24-hour broadcast television to today's constant engagement with social media - women and men have been covering a variety of roles across a diverse portfolio of media outlets. Yet, the multiple ways in which gender has been represented by the media has only been a subject of discussion and study in recent decades. Some say that this is largely due to the emancipation of women and feminism, the growing acceptance of the LGBTQ communities, and the spread of the internet and social media, which empower its users to make their voices heard. However, one look at the news media in recent months is sufficient to evoke the feeling that both feminism and LGBTQ communities are still in their infancy. Current developments in Brunei, US President Trump's famous "Grab them by the pussy" remark, or the \#MeToo movement, which was started in 2006 by African American activist Tarana Burke, but only gained momentum when it was utilised to publicly shame Hollywood Mogul Harvey Weinstein are all symptoms of a divided world - with those fighting for equal rights for all genders on one hand, and those desperately trying to cling on to archaic ideals of an old patriarchy on the other. Simultaneously, these phenomena all raise issues of class, ethnicity and belonging, and reinforce existing white, western stereotypes, a narrative that is highly problematic, and in which the media play a crucial role. This issue of for(e)dialogue hopes to add to the ever-growing field of Media and Gender studies by offering up new insights into the important role of different media platforms in shaping and influencing the narratives around gender and the many nuances attached to it, and further the ways in which they are actively appropriated by media users and audiences. 


\title{
A Contemporary Outlook on Media and Gender
}

Not long after Donald Trump was elected president of the United States of America, a video surfaced that showed him bragging that he can get anything he wants, and referring to women in particular that one should simply "Grab them by the pussy". While this video dated back to 2005, the outrage it received in 2016 was enormous, with many women's rights organisations calling for his immediate removal from public office. His statement was widely discussed and he was rightly attacked over it, yet others argue that Trump is mainly an example of a part within society that is still highly influenced by old-fashioned and outdated views on traditional gender roles. As Julia Wood (1994) argues

\begin{abstract}
A [...] theme in mediated representations of relationships between women and men is representation of women as subject to men's sexual desires. The irony of this representation is that the very qualities women are encouraged to develop (beauty, sexiness, passivity, and powerlessness) in order to meet cultural ideals of femininity contribute to their victimization. Also, the qualities that men are urged to exemplify (aggressiveness, dominance, sexuality, and strength) are identical to those linked to abuse of women" $(1994,236)$
\end{abstract}

Trump's bragging that a man should just take a woman if he wants to, especially in such a sexist context, is yet another prime example of the archaic, yet still existing, image of a woman as an 'object' a man can and should possess. Precisely this is the nexus in which Trump's remark could be situated, for he is a senior, white, upper-class male, who was privileged all his life, and who grew up during a period in time in which the equal position of a woman was still a novelty and highly contested by the male role models he would have orientated himself on. While his behaviour and thinking can not be excused and should not be tolerated at this time of age, especially considering his public role of influence and authority, it highlights the importance of media platforms in publicising these narratives and offering a format in which they can be contextualised in the contemporary discourse, and hence be discussed and criticised.

Yet, the function of the media as a mode of representation of gender roles is not a novel 
phenomenon. In fact even the earliest forms of motion pictures played a vital role in conveying images of men and women that shaped the way gender was experienced for centuries. For instance, this has most recently been acknowledged by the Museum of Modern Art in New York City with an exhibition of old film posters dating back to the early $20^{\text {th }}$ century. The Guardian ${ }^{1}$ published a feature of this exhibition on April 9, 2019, with the title "It's not about nostalgia': re-examining gender roles in film posters", connecting the notion that gender roles have long been a subject of interest in the media, and furthermore, that it is the public interest that warrants such an important public exhibition. Nadja Sayej, the author of the article further points out that "Long before the Harvey Weinstein claims and the \#MeToo movement, there was bad behavior in the Hollywood film industry", a statement which refers to a quote by Co-Curator Brittany Shaw, who elaborates further that "I think a lot of toxic things happened in Hollywood but there were liberated people," said Shaw. "You can find queer and feminist moments, but none of it will be perfect" (The Guardian, ibid). What these points suggest are that gender roles have always been both of interest to the world of film and television, as well as a subject of them, and that changes have started to take place over the past decades that are still ongoing.

The connection between motion pictures and the representation of gender is particularly crucial, as the medium of film is far more popular than, for instance, broadsheet journalism. Taking this argument further, as Wood argues "Highly popular films such as Lethal Weapon, Predator, Days of Thunder, Total Recall, Robocop Die Hard, and Die Harder star men who embody the stereotype of extreme masculinity. Media, then reinforce long-standing cultural ideals of masculinity: Men are presented as hard, tough, independent, sexually aggressive, unafraid, violent, totally in control of all emotions, andabove all-in no way feminine" $(1994,232)$. These stereotypes and their constant reinforcement by such popular movie franchises are problematic, as they confirm on one hand to impressionable men how they should behave, and who they should strive to be like, but they simultaneously suggest to both men and women what the role of the opposite gender should look like. Wood points out further that 
Media have created two images of women: good women and bad ones. These polar opposites are often juxtaposed against each other to dramatize differences in the consequences that befall good and bad women. Good women are pretty, deferential, and focused on home, family and caring for others. Subordinate to men, they are usually cast as victims, angels, martyrs, and loyal wives and helpmates. Occasionally, women who depart from traditional roles are portrayed positively, but this is done either by making their career lives invisible, as with Claire Huxtable, or by softening and feminizing working women to make them more consistent with traditional views of femininity. $(1994,233)$

And while some might argue that the examples quoted by Wood in her 1994 text are outdated, a look at more recent movies, such as the John Wick series (2014 \& 2017), or the Taken franchise with Liam Neeson $(2008,2012$ \& 2014), all replicate the same male attributes that, for example, Bruce Willis portrayed in the Die Hard films. The fact that these type of films do not appear to lose any of their appeal to movie audiences, highlights that there is still a strong demand for portrayals of 'typical' Alpha-male characters.

However, film and TV are not the only media platforms that have contributed to the way gender roles are understood and lived within society. News journalism, digital media and social media all play vital parts in the shaping, reshaping and reinforcing of gender roles. Looking at recent examples of the role of news journalism in the creation of narratives around gender, Sky News published an article about UK signer Sam Smith, who openly discussed the fact that he identifies as non-binary in an interview on March 18, 2019. He is quoted in the article to have said: "You are just you. You are a mixture of all different things. You are your own special creation. That's how I see it." ${ }^{2}$ Examples like these show just how much gender stereotypes have changed, but also how different media platforms engage with the topic at hand. In this specific case, Sky News offer an open platform for the discussion of non-binary gender identities, something that would have been unthinkable in the early $20^{\text {th }}$ century, for instance.

This is at least true for Western countries, however, as the current developments in Brunei 
highlight, LGBTQ communities are still not accepted or even tolerated in large parts of the world today. However, while Western media outlets were quick to respond and criticise the announcements of the Sultan of Brunei that from April $1^{\text {st }}, 2019$, gay people would face death by stoning under a new tightening of the strict Sharia Laws, it raises the question as to why Western media outlets are quick to condemn intolerance and homophobia in some cases, yet largely ignore similar events in the West, such as the La Madame attack in Mexico in 2016, which happened just one month prior to the Pulse shootings in Orlando, Florida $^{3}$. BBC News, for instance, published an article on March 29, 2019, that focused on the call of celebrities to boycott large hotel chains that are owned by the Brunei Investment Agency. The article quotes US actor George Clooney, who said "In the onslaught of news where we see the world backsliding into authoritarianism this stands alone," [...] "Brunei is a Monarchy and certainly any boycott would have little effect on changing these laws", [...] "But are we really going to help pay for these human rights violations?" ${ }^{4}$ However, at the same time there is no mention being made to other atrocities committed against members of the LGBTQ community, which implies once again that ethnicity and class play an additional role in these cases. The connection between public broadcast platforms, celebrities and the public, however, seems to be vital in cases that call for social action. For once, the publicising of a matter such as this by the media helps to raise awareness of injustice, while the outcry of celebrities helps to further push the subject into the public realm. The wide reach of media platforms must never be underestimated, especially not in matters that cause outrage and demand action, however, they must also be understood in their critical complexity, and the power they have in reinforcing stereotypes not purely about gender, but also class and ethnicity.

\section{About this issue:}

In this issue of for(e)dialogue, the connection between a variety of media platforms and their interaction with and impact on the different representations of gender are investigated further, with the aim to further the understanding of how we perceive gender in todays media culture. The following chapters will provide a variety of view points on different aspects of mediated gender stereotypes, and situate them within the broader field of gender and media studies. 
Looking closely at an example of a contemporary TV show, Jonathan Buck engages in chapter 1 in a critique on RuPaul's 'Drag Race' reality show. He recognises how on the one hand, the show offers a quite welcoming platform for communicating drag culture to a broader audience, while on the other hand, he highlights the numerous ways in which the show via its presenter and structure creates a depoliticized and homogenous account for drag culture, and based on a liberal attitude promotes individualistic logic and harsh competition as the recipe for success. By doing so, he takes a different look at the collective values that were founded in the the drag community and their struggles over the years.

Studying a very different aspect of media and gender relations, Annalisa Ciro seeks to explain the roots of homophobia in America's hip-hop scene in chapter 2. She aims to show how the music genre of the marginalised and oppressed did not become homophobic on its own but rather was unavoidably penetrated by hyper masculine and misogynistic context that has been spread and holds a dominant position across American society. At the same time though, she points out the benefits of having emerging queer hip-hop artists and their allies gaining space in the recent hip-hop scene.

Using feminist theories on the body as her theoretical lens in chapter 3, Sara Persson analyses the patterns of the representation of giving birth, by focusing on five popular films and their relation to real life birth giving practices. She seeks to explain how certain scenes which do not conform to what is generally considered 'normal' are often thought of as bizarre, and subsequently become 'othered'. Furthermore, her paper aims to trace potential connections between the representation of birth as it is communicated in the eight scenes she analyses, and the director's own backgrounds of gender, social class, ethnicity and other aspects of their life.

In Chapter 4, Joshua Harris applies a Foucauldian approach to establish how the social normalization of the gender occurs, with a view to discuss how the internet has provided a fertile ground for 'Generation Z' activists to campaign for transgender politics. Harris further tries to highlight the evolution of transgender politics through time. He concludes by 
proposing a way in which the blogging platform 'Tumblr' could enhance the struggles against social normalisation, as well as reinforce the transgender discourse that is taking place in the online public sphere.

In the final paper of this issue of for(e)dialogue, Rebecca Jones' analysis takes its beginnings from the foundations of ecofeminism and vegetarian/vegan feminist theory. She argues that the online environment has undoubtedly proven to be a useful place for raising prominent feminist discourses on animal rights. However, Jones notes further, that the same online environment remains affected by patriarchal notions, and she invites the reader to think how the gendered online context impacts on the feminist discourse on animal rights itself.

We hope that the variety of issues addressed in this third issue of for(e)dialogue helps to advance the debates revolving around the relationship between the media and gender roles, and that it challenges its readers to critically assess which part media platforms have played in shaping and developing stereotypes, and what role they play in the advancement, but also the restricting, of equality today. We would like to express our sincere gratitude to $\mathrm{Dr}$ Maria Rovisco and Dr Jessica Noske-Turner, who have been invaluable in getting this issue of the ground. A huge thank you also to Yvonne Lee at the School of Media, Communication and Sociology and Dr William Farrell at the David Wilson Library for their continued support in all matters IT. Finally, we would like to thank our authors for their enthusiasm in producing thought-provoking and engaging papers to contribute to this issue, we hope you are as proud of this issue as we are.

\section{Contact the Editors:}

Nerina Boursinou mnb7@le.ac.uk

Sandra Kaulfuss sk630@le.ac.uk 


\section{References}

BBC News, March 29, 2019, https://www.bbc.co.uk/news/world-asia-47744566

Out Magazine, June 16, 2016, https://www.out.com/news-opinion/2016/6/16/month-pulsetragedy-gunmen-killed-seven-mexican-gay-bar-attack

The Guardian, April 9, 2019, https://www.theguardian.com/film/2019/apr/09/what-pricehollywood-moma-exhibition-film-posters-gender-roles

Sky News, March 18, 2019, https://news.sky.com/story/sam-smith-i-dont-identify-as-maleor-female-11669552?fbclid=IwAR1EQQxlyp4a-

pjKVzrhAKvJLMjgcqQfWCXBMXzlxkMuzO5e7OM4FAHJy9E

Wood, Julia T. (1994) Gendered Lives: Communication, Gender and Culture, Wadsworth

Publishing: Belmont 